\title{
La organización de las elecciones en el contexto de los comicios de 2012. Entrevista con el doctor Leonardo Valdés Zurita, presidente del Consejo General del Instituto Federal Electoral, 6 de septiembre de 2011
}

1. ¿En qué medida la reforma constitucional de 2007 beneficia a nuestros procesos democráticos?

Los actos anticipados de campaña, la intervención de instancias ajenas al proceso electoral y la inequidad en la contratación de propaganda electoral en los medios de comunicación electrónicos en la elección de 2006 constituyeron antecedentes que el Congreso de la Unión consideró para promover cambios a la Constitución Política de los Estados Unidos Mexicanos (CPEUM) y a la legislación electoral federal.

Más allá de las particularidades y aspectos de orden estrictamente operativo, la reforma electoral de 2007 comprende cuatro vertientes: a) fortalecimiento del régimen de partidos políticos; $b$ ) una fórmula para calcular y distribuir el financiamiento público que se invierte en la democracia; $c$ ) fiscalización de los recursos de los partidos políticos, y d) un nuevo régimen de acceso a radio y televisión.

De esta manera, para fortalecer la naturaleza de las organizaciones partidistas, la última reforma privilegió la afiliación individual en los partidos políticos y prohibió aquella de carácter gremial.

Con respecto al financiamiento público, la determinación del monto destinado a las actividades ordinarias se calcula ahora multiplican- 
do el número total de ciudadanos inscritos en el padrón electoral, por el 65\% del salario mínimo vigente en el Distrito Federal.

En materia de fiscalización, la reforma dispuso que las cuentas, fondos o fideicomisos abiertos por los partidos políticos para la inversión de sus recursos líquidos no están protegidas por los secretos, bancario, fiscal y fiduciario. Ahora el Instituto Federal Electoral (IFE) puede obtener información directa del sistema bancario nacional, para conocer los montos de las cuentas que manejan los partidos políticos.

Con los cambios al régimen constitucional y legal en materia electoral, se instauró también en México un nuevo modelo de comunicación política, que entre otros elementos, refrenda el derecho que tienen los partidos políticos para acceder a los medios de comunicación en forma permanente; utilizando para ello, el tiempo oficial con que cuenta el Estado.

De esta manera, por mandato del legislador, el IFE se convirtió en la única autoridad encargada de administrar, distribuir y monitorear los promocionales de carácter político-electoral de las organizaciones partidistas y autoridades electorales.

Por otra parte, el nuevo marco constitucional y legal establece también la prohibición de utilizar propaganda encaminada a la promoción personalizada de los servidores públicos y de emplear expresiones que denigren a las instituciones públicas, a los partidos políticos y calumnien a las personas.

De este modo, el nuevo modelo de comunicación política y la reforma electoral en su conjunto están encaminados a fortalecer el papel de la autoridad electoral, a respetar los derechos constitucionales y a garantizar mejores condiciones de equidad y transparencia en la competencia electoral.

2. ¿Cuáles son las principales acciones implementadas por el IFE, a partir de la reforma de 2007?

Las reformas constitucional y legal dieron al IFE 53 nuevas atribuciones. Para su implementación fue necesario llevar a cabo una gran adecuación a la normatividad interna que no se había experimentado desde 1996. Concretamente se aprobaron 21 reglamentos y 3 normas reglamentarias, además de importantes modificaciones estructurales. 
Entre ellas están el procedimiento para realizar el recuento de la votación; los nuevos procedimientos especializados sancionadores; la nueva Unidad de Fiscalización de los Recursos de los Partidos Políticos, y el nuevo modelo de acceso a la radio y la televisión para los partidos políticos y las autoridades electorales.

El nuevo procedimiento especializado sancionador consiste en un proceso sumario para la resolución de quejas en materia electoral. Con éste, deben de resolverse agravios en 5 días y obliga a sesionar constantemente en el Consejo General así como en los consejos locales y distritales. Esto lógicamente se multiplica con la extensión y complejidad que adquirirá la competencia por el poder político del próximo año.

Por otro lado, el IFE ahora cuenta con una Unidad de Fiscalización que sin las limitantes de los secretos fiscal, fiduciario y bancario revisa los recursos de los partidos políticos y agrupaciones políticas nacionales, obligándolos a respetar los topes de gastos de campaña y el origen de los recursos.

Finalmente, el nuevo modelo de comunicación política de nuestro país se caracteriza porque la única vía para difundir mensajes electorales en la radio y la televisión es a través de los tiempos oficiales del Estado. Para ello el IFE debió:

1) Desarrollar una serie de normas, reglamentos, acuerdos y criterios coherentes para brindar certeza y precisión operativa a los concesionarios y permisionarios de los medios electrónicos, partidos políticos, gobiernos de todos los niveles y autoridades electorales del país, entre otros.

2) Establecer relaciones institucionales para la regulación efectiva de 2043 estaciones de radio y canales de televisión de todo el país.

3) Desarrollar un equipo tecnológico propio que permita: recibir, calificar la calidad, catalogar, enviar, detectar, grabar, archivar y reportar los materiales que partidos y autoridades colocan para su difusión.

4) Diseñar e instalar un dispositivo legal, técnico y operativo para sancionar con prontitud cualquier conducta ilegal, transmitida en las señales radioeléctricas del país, que fuese denunciada o detectada por la propia autoridad electoral. 


\section{3. ¿Existen aún pendientes en el proceso de implementación de dicha reforma?}

La reforma electoral de 2007-2008, fue implementada por el IFE de manera puntual previo a la realización del proceso electoral federal 2008-2009.

El Informe General sobre la Implementación de la Reforma Electoral durante el proceso 2008-2009, conocido como el Libro Blanco, da cuenta de las modificaciones normativas, estructurales, administrativas y operativas, realizadas por el IFE, para cumplir con los mandatos constitucional y legal en tiempo y forma. Además, describe la aplicación de este nuevo modelo en la organización de los comicios federal y los 15 procesos locales celebrados en ese año.

Se ha dicho que la elección de 2009 puso a prueba la viabilidad de la reforma electoral y los resultados lo constatan.

Sin embargo, no existe una reforma definitiva. Los modelos electorales son perfectibles y la aplicación de la nueva normatividad nos permitió identificar algunas cuestiones susceptibles de ser precisadas para consolidar el nuevo modelo electoral. Entre ellas:

1) En materia de radio y televisión se consideró pertinente realizar reformas a la ley a efecto de que el modelo de comunicación política permitiese acumular los tiempos asignados a los programas de los partidos políticos, para disponer de un espacio mayor a los 30 segundos asignados a sus promocionales, para realizar propuestas con mayor contenido informativo.

2) El Instituto fue enfático al señalar la falta de una ley reglamentaria del artículo 134 constitucional, que detallara la forma en que deben sancionarse las conductas de los funcionarios públicos, así como el uso de los recursos públicos asignados al cumplimiento de sus funciones, que pudieran influir en la equidad de las contiendas electorales.

3) La conveniencia de ajustar las reglas para la realización de los cómputos distritales, ante la eventualidad de que se abra un gran número de paquetes electorales, en los que confluyan tres elecciones.

La necesidad de éstas y otras precisiones legales, como la flexibilización del modelo elegido por el legislador para que los ciudadanos 
residentes fuera del territorio nacional puedan ejercer su derecho a voto, se incluyen en el citado Libro Blanco, el cual fue presentado a los legisladores a principios del 2010. Lamentablemente no fue posible concretar la reforma electoral.

4- ¿Cómo afecta al próximo proceso electoral la inexistencia de una ley del derecho de réplica y una ley de propaganda gubernamental? Mencione las acciones que ha implementado el IFE al respecto y la jurisprudencia sobre el particular.

El IFE recientemente modificó su normatividad reglamentaria para enfrentar los retos del próximo proceso electoral federal 2011-2012.

La actualización a la normatividad interna que aprobó el Consejo General en junio y los primeros días de julio del presente año, tuvo como propósito el fortalecimiento de los principios de certeza jurídica y eficacia para la correcta organización de los comicios de 2012.

Dentro de los cambios y adiciones que se realizaron a la normatividad del IFE, se modificó el Reglamento de Quejas y Denuncias para incorporar la figura del derecho de réplica como una garantía que deben tener los precandidatos, candidatos y partidos políticos para ejercer este derecho respecto de la información que presenten los medios de comunicación, cuando consideren que la misma ha deformado hechos o situaciones referentes a sus actividades, en términos de los dispuesto por el artículo 6o. de la CPEUM y 233, párrafo 3 del Cofipe.

Esta adición responde también al criterio emitido por la Sala Superior del Tribunal Electoral del Poder Judicial de la Federación en el recurso de apelación SUP-RAP-175/2009, en el que, en esencia, determinó que la vía para hacer efectivo el derecho de réplica es el procedimiento especial sancionador, para que en un plazo breve, exista la posibilidad de formular una rectificación sobre los hechos o situaciones que se estiman deformados.

Estas consideraciones legales, dieron lugar a la tesis relevante VII/2010, emitida por el Tribunal, cuyo sustento jurídico se apoya en la prontitud para resolver el procedimiento especial sancionador, ya que si este derecho se ejerce en un plazo ordinario, posterior a la difusión de la información que se pretende corregir, la réplica ya no tendría los mismos efectos, por lo que su expeditez se justifica ante la 
brevedad de los plazos en los que se desarrolla el proceso electoral y la definitividad que caracteriza cada una de sus etapas.

Ahora bien, para la propaganda política, electoral y gubernamental, la Comisión de Quejas y Denuncias discute actualmente una versión preliminar del reglamento que regulará las distintas hipótesis en esta materia.

En dicha reglamentación, también se prevén los casos para la presentación de denuncias o quejas por la transmisión o difusión de este tipo de propaganda, tomando en cuenta los criterios que en diversos recursos de apelación ha resuelto el Tribunal.

La Comisión de Quejas y Denuncias estudia la posibilidad de que este Reglamento sea aprobado por el Consejo General en septiembre de 2011, para que se utilice durante el proceso electoral venidero. Para tal efecto, se ha establecido un grupo de trabajo al interior de la Comisión, en la que participan las representaciones de los partidos políticos y del Poder Legislativo, para generar un mayor consenso respecto de los supuestos jurídicos que se plantean en esta normatividad.

5. ¿En qué medida afecta al funcionamiento del Instituto Federal Electoral la falta de nombramiento de los tres consejeros electorales que la Cámara de Diputados debió haber designado desde octubre de 2010? ¿Qué implicaciones tiene, ha tenido o tendrá esa falta de nombramiento?

La elección de consejeros electorales es una atribución de la Cámara de Diputados, por lo el IFE es un organismo que respeta los ámbitos de competencia que establece la CPEUM.

Aunque la ausencia de los tres consejeros electorales ha propiciado mayores cargas de trabajo para las comisiones permanentes del Consejo General, los seis consejeros electorales cumplen con absoluta responsabilidad las disposiciones que establece la ley.

El IFE está atento a la decisión de la Cámara de Diputados en esta materia y apoyará el trabajo de los consejeros electorales que sean designados por el órgano legislativo.

Resulta importante destacar que la renovación escalonada de los consejeros electorales permite aprovechar la experiencia acumulada e incluir permanentemente las posturas y expresiones que reflejan la 
pluralidad y la dinámica que tiene la sociedad mexicana. El IFE tiene plena certeza que la elección de los consejeros electorales constituye un proceso que incorpora a las mejores personalidades del país.

6. ¿Qué implicaciones tiene la falta de nombramiento de los titulares de dos direcciones ejecutivas (RFE y DEPPP) para el funcionamiento del IFE y para los preparativos del proceso electoral federal de 2011-2012?

Según lo dispone los artículos 118 y 119, incisos e, del Cofipe, los directores ejecutivos son designados por el Consejo General, a propuesta del consejero presidente.

De 1991 a 1993 esta facultad correspondió al director general. Con la reforma de ese año, se otorgó al máximo órgano de dirección tal facultad, debiendo reunir la anuencia de las dos terceras partes de sus integrantes sobre la propuesta planteada por el director general.

Posteriormente, la reforma de 1996 eliminó las figuras de director y de secretario generales y creó la presidencia del Consejo General y la Secretaría Ejecutiva. Con esta misma reforma se otorgó la facultad al presidente del Consejo General para proponer al máximo órgano de dirección el nombramiento de los titulares de la estructura ejecutiva (art. 83 inciso e) y se suprime la necesidad de reunir una mayoría calificada.

Sin lugar a duda, el otorgar la facultad de designación al cuerpo colegiado, tuvo como finalidad lograr un consenso entre los integrantes del máximo órgano de dirección para elegir a los mejor preparados.

Es del conocimiento público que desde el pasado mes de noviembre de 2010, la integración del Consejo General se encuentra en una situación excepcional.

La presidencia se comprometió a esperar que el Consejo General estuviera integrado plenamente, para proponer el nombramiento de los titulares de las direcciones ejecutivas del Registro Federal de Electores y de prerrogativas y partidos políticos.

Han pasado más de 10 meses y esto no ha sucedido.

La situación ha cambiado. A dos meses de iniciar el proceso electoral federal 2011-2012, y a pesar de que los encargados de despacho designados han realizado un papel profesional que ha permitido que 
las responsabilidades de esas direcciones ejecutivas se hayan realizado de forma eficiente, el IFE no debe iniciar el proceso electoral sin nombrar a sus titulares.

Es por ello que por responsabilidad, y en uso de las atribuciones conferidas por la ley, el pasado 25 de agosto, la presidencia presentó al Consejo General las propuestas de profesionales especialistas en esas áreas que cumplían con el perfil requerido por la normatividad para ocupar los cargos.

La diversidad de visiones propia de los órganos colegiados y la falta de acuerdo sobre la interpretación de uno de los requisitos legales, derivó en que sólo una de las propuestas fuera aceptada, es preciso indicar, con el apoyo de todos integrantes del Consejo General.

7. ¿Cómo se explican las importantes diferencias de criterio entre los consejeros para determinar sanciones a diversos actores como consecuencia de procedimientos sancionadores? ¿Qué implicaciones tiene ello en términos de la fortaleza institucional del IFE y de generación de confianza entre la ciudadanía de cara a las elecciones de 2012?

En primer lugar, es preciso indicar que las diferencias de criterio entre los consejeros electorales no se presentan únicamente a partir de los procedimientos sancionadores. En realidad, estas diferencias de opiniones son parte cotidiana de los procesos de deliberación y decisión del Instituto Federal Electoral. Como órgano colegiado, la pluralidad y el debate son rasgos característicos no solamente de la Institución, sino de un sistema democrático.

Estas diferencias se explican desde las distintas perspectivas de vida, formación profesional y personal que cada integrante del Consejo General pueda tener. Sin embargo, a pesar de estas diferencias, es preciso mencionar que todas las decisiones institucionales se realizan con base en la ley. La pluralidad y el debate nos otorgan el derecho a opinar y a disentir, pero siempre apegados al marco normativo que rige la vida del IFE.

Finalmente, estas distintas visiones no deben ser consideradas como una debilidad institucional. Al contrario, en un órgano colegiado aspiramos a que el debate sea amplio, incluyente, auténtico y esto 
no puede ser logrado sin el abanico de ideas y perspectivas con que contamos. La pluralidad en el IFE, como en un sistema democrático, es una fortaleza. Atrás están los tiempos donde una sola forma de pensar dominaba el horizonte político; la democracia no sólo significa contar con distintas opciones, sino contar con una pluralidad de ideas.

8. ¿Ha afectado la credibilidad del IFE ante la sociedad y ante los actores políticos, la polémica pública en torno a algunos manejos administrativos del IFE, a partir de una serie de investigación iniciadas por la Contraloría General de ese Instituto? ¿Qué se ha hecho al respecto?

Ante la creciente importancia de los medios de comunicación en la vida diaria, toda información que se difunda en éstos, tiende a provocar un impacto en la percepción de los ciudadanos. Lo que le sucede al IFE no es la excepción.

Es evidente que desde hace varios años la mayoría de las encuestas muestran que el IFE es una de las instituciones que goza de mayor confianza entre la población. Sin embargo, a partir de la reforma electoral de 2008, el Instituto ha enfrentado nuevos retos que han sido difundidos no son necesariamente de manera neutral, como la administración del tiempo en radio y televisión, que ha derivado en una mayor presencia mediática del funcionamiento del IFE y de sus decisiones. Adicionalmente, la creación de la Contraloría General, establecida en la Constitución, ha contribuido a que el IFE sea una institución con paredes de cristal; intensivamente escudriñada. De hecho, no existe otra institución pública que sea más vigilada, auditada y supervisada que el IFE. En este contexto es natural que los informes que por ley emite la Contraloría General y la insistencia con la que se ha difundido el resultado de éstos en los medios de comunicación, impacte la imagen del Instituto. Sin embargo, es de señalar que el impacto sido marginal y el IFE sigue siendo una de las instituciones que gozan de la mayor confianza ciudadana. 
9. ¿Cómo afecta la decisión de no realizar ajustes al marco legal de cara al próximo proceso electoral?

Durante la implementación de la reforma electoral y después del ejercicio democrático de 2008-2009, así como la colaboración en la organización de 38 elecciones locales, el IFE detectó áreas de oportunidad para precisar el nuevo modelo electoral.

Según lo dispone el texto constitucional, para que las modificaciones al marco normativo fueran aplicables al proceso electoral 20112012, se deberían haber realizado con 90 días de antelación a su inicio, situación que no ocurrió.

Es por ello que el IFE, ante la eventualidad de que se actualizara esta situación, se dio a la tarea de ajustar su normatividad interna, como ya se explicó anteriormente. Algunos de estos cambios han sido polémicos y crearon suspicacias. Por ello es preciso subrayar que todas las modificaciones normativas se hicieron en estricto apego al marco legal, respetando la esfera de competencia de las autoridades y con el único objetivo de crear certeza en el proceso electoral en puerta.

Lo ideal habría sido que se reformara la ley. Pero si los acuerdos políticos no se concretaron, los ciudadanos deben estar seguros que con el marco normativo actual, el IFE puede y va a organizar unas elecciones como las que ha venido organizando desde hace 20 años: profesionales, transparentes y equitativas, que brinden legitimidad a los actores, pero sobre todo certeza a la ciudadanía.

10. El IFE acaba de modificar varios reglamentos en ese sentido. ¿Cómo beneficia ese hecho al funcionamiento institucional y qué riesgos se enfrentan?

Beneficia en el sentido de que se precisan diversos procedimientos que permiten una mejor operación institucional y un trabajo más eficiente.

Durante junio y los primeros días de julio, el Consejo General del IFE, aprobó modificaciones a 9 reglamentos internos, asimismo se expidió el acuerdo sobre las reglas de imparcialidad en la aplicación de 
los recursos públicos a que se refiere el artículo 347, párrafo 1, inciso $c$, del Cofipe.

Todos revisten importancia particular en sus ámbitos de aplicación. Sin embargo, en la opinión pública se hizo eco de dos en particular: el Reglamento de Radio y Televisión y la eventual reglamentación del derecho de réplica en materia electoral.

A grandes rasgos, las presiones normativas fueron las siguientes:

1) El 23 de junio se aprobó el nuevo Reglamento de Quejas y Denuncias, en el cual se incluyen definiciones sobre actos anticipados de pre campaña y campaña; se puntualiza el procedimiento para la adopción de medidas cautelares; los mecanismos para la tramitación de procedimientos ordinarios y especiales sancionadores, indicando que conforme a la sentencia del TEPJF, este último será el medio de defensa que deberá utilizarse ante una eventual vulneración del derecho de réplica.

2) En esa misma fecha se aprobaron modificaciones al Reglamento del Instituto Federal Electoral en Materia de Transparencia y Acceso a la Información, así como al Reglamento de Sesiones del Órgano Garante de la Transparencia.

3) En materia de fiscalización, el 4 de julio pasado el Consejo General aprobó tres instrumentos normativos: el Reglamento de Fiscalización, que regula el aspecto sustantivo e incluye el tema relativo al uso del 2\% destinado a la promoción de las mujeres; el Reglamento de Procedimientos en Materia de Fiscalización, que incorpora aspectos procedimentales para el trámite de quejas y procedimientos oficiosos, y el Reglamento para la Liquidación y Destino de los Bienes de los Partidos Políticos Nacionales que pierden su registro.

4) Se aprobaron importantes modificaciones al Reglamento de Sesiones de los consejos locales y distritales, a efecto de precisar algunos procedimientos, particularmente el relativo a los cómputos distritales.

5) También el Reglamento de Sesiones del Consejo General fue reformado, a efecto de clarificar e incluir algunas prácticas ya institucionalizadas.

6) En materia de radio y televisión, se realizaron importantes reformas reglamentarias; éstas son quizá las que han causado mayor polémica por parte de un sector específico. Su finalidad es clara: que 
la sustitución de materiales se realice de forma más ágil para que los ciudadanos cuenten con más y mejor información para formarse un criterio al emitir su voto.

Es preciso indicar que algunos de estos cuerpos normativos fueron impugnados ante el TEPJF, quien, en uso de sus facultades jurisdiccionales ordenó al Consejo General del Instituto realizar precisiones; ninguna de ellas, hasta ahora, ha sido sustancial, por lo que se puede afirmar que en esencia los reglamentos que se van aplicar son los mismos que se analizaron y aprobaron en el IFE. El TEPJF ha coincidido con el ánimo que guió al IFE para realizar las reformas: ofrecer a ciudadanos y partidos mayor certeza en los procedimientos.

11. ¿Qué nivel de cumplimiento de la nueva normativa se espera, sobre todo por parte de los medios de comunicación?

El pasado 27 de junio, el Consejo General aprobó diversas modificaciones al Reglamento de Acceso a Radio y Televisión en Materia Electoral orientadas a precisar los conceptos de cobertura; mapa de cobertura; pauta e intercampaña; envío de materiales a los concesionarios y permisionarios de la radio y la televisión; a la transmisión de los pautados aprobados por la autoridad electoral, entre otros.

El ajuste normativo interno fue en respuesta a la responsabilidad institucional que recupera la experiencia acumulada de administrar los tiempos oficiales en 38 procesos electorales locales y 12 elecciones extraordinarias. Por supuesto, tenemos el aprendizaje del proceso electoral federal de 2009, de 11 elecciones locales coincidentes durante ese año y de procesos electorales llevados a cabo en 15 entidades federativas durante 2010.

La relación que se ha tenido con la Cámara de la Industria de la Radio y la Televisión ha permitido que el nuevo modelo de comunicación política haya tenido un incremento en el porcentaje de cumplimiento, en cuanto a la transmisión de mensajes pautados por parte del Instituto; por ejemplo, en el proceso electoral federal de 2009 se tuvo un cumplimiento del 92.39\%; en el 2010 hubo un cumplimiento del $97.70 \%$, y en 2011 , se tuvo un cumplimiento de $97.40 \%$ en los estados que tuvieron elecciones. 
Lo que esperamos con este nuevo ajuste reglamentario es que los concesionarios y permisionarios del país demuestren una vez más el compromiso que tienen no sólo con la legalidad, sino también con los ciudadanos y la democracia en México, manteniendo los niveles de cumplimiento que hasta el momento han mostrado.

12. Ante la creciente intensidad discursiva entre los actores políticos y el "destape" público de cada vez más aspirantes presidenciales ¿cuál debe ser la política institucional como organizador, regulador y/o árbitro de las disputas electorales?

Es cierto que en los medios de comunicación se ve con mayor frecuencia a un número mayor de ciudadanos buscando convertirse en candidatos a la Presidencia de la República. De la misma forma, también apreciamos mensajes y publicidad de otros ciudadanos que buscan ocupar otros puestos de elección popular.

Sin embargo, lo cierto es que todos los sujetos regulados deben ceñirse a la normatividad electoral, incluyendo a la autoridad. Todos deben de observar la ley y respetar el Estado de derecho, con el cual sin duda avanzaremos hacia la construcción de un sistema democrático más sólido para nuestro país.

No obstante, el hecho de cumplir la ley no debe limitar la libertad de expresión de ideas y expectativas de los ciudadanos. Antes de iniciar el proceso electoral, el próximo 7 de octubre, todas y todos los ciudadanos no sólo pueden, sino deben expresarse como gusten. Esta libertad de expresión, de intereses y de preferencias, sean éstas de índole económico y social o, como en este caso, político, se encuentra no sólo garantizada por nuestra Constitución, sino es parte integral del ejercicio democrático.

En el pasado, la participación y la libre expresión ciudadana estaban coartadas. Anteriormente, el "destape público" debía esperar no los plazos establecidos por la ley ni la maduración de las preferencias personales, sino las instrucciones del liderazgo político. Ahora tenemos una sociedad dinámica, moderna y plural donde afortunadamente las y los ciudadanos pueden expresarse como gusten.

Aún no inician los tiempos electorales. Apenas en la primera semana de octubre de este año el Consejo General del IFE dará inicio for- 
malmente al proceso electoral federal 2011-2012. Es hasta ese simbólico inicio formal del juego en el que se disputará el poder político que el IFE, como árbitro electoral, hará cumplir la normatividad: no antes.

De tal suerte, lo que tenemos que hacer es esperar los tiempos electorales. Es hasta entonces que aplicaremos la ley con cuidado y con rigor, a fin de tener un proceso electoral equitativo, abierto y en libertad para que los ciudadanos puedan elegir a sus representantes.

\section{3. ¿Cuáles son los principales riesgos que se avizoran en el próximo proceso electoral?}

Las democracias son puestas en riesgo cuando las reglas del juego no son respetadas. La aceptación de las reglas de la democracia por parte de todos los actores políticos y sociales es lo que da sentido y caracteriza una democracia auténtica en la que el poder político se determina con el sufragio. Sin embargo, el respeto a los términos de la competencia y a los resultados que de ella derivan son procesos que toman tiempo en ser interiorizados.

Durante las últimas dos décadas, y a través de una transición votada, en México hemos generado instituciones que garantizan contar con elecciones competidas y transparentes con resultados limpios. Sin embargo, este marco legal e institucional también debe ser respetado por sus sujetos obligados. El próximo proceso electoral será el más grande en la historia del país, por lo que la aceptación de sus términos y resultados es de la mayor importancia para consolidar nuestra democracia.

En 2012 se llevarán a cabo 15 elecciones locales donde se elegirán además del presidente de la República, 128 senadores y 500 diputados federales, a 925 representaciones municipales, 559 curules en los poderes legislativos locales, 6 gobernadores y un jefe de gobierno. En todas estas elecciones estará involucrado el Instituto Federal Electoral por mandato constitucional en los temas de radio y televisión, en la georreferenciación de los ciudadanos, en la fiscalización, e incluso en actividades de arbitraje electoral por conductas que se consideran no apegadas al marco legal.

Lo anterior debe ser evaluado a la luz de las dimensiones de la contienda electoral venidera. En nuestra historia, nunca antes se había 
disputado el poder político - a través de tantos cargos de elección popular - de manera tan amplia en las urnas. De ahí la importancia de que los sujetos regulados se apeguen a la CPEUM, al Cofipe y a los demás reglamentos de ellos emanados. Todos, como ciudadanos, debemos contribuir a que las reglas y procedimientos electorales sean una rutina aceptada. Debemos contribuir a que la próxima contienda se decida a través de las urnas y que sus resultados sean aceptados, haciendo que en nuestra democracia el segundo lugar acepte la derrota, y el primer lugar haya triunfado con base en las reglas establecidas.

14. El clima de violencia en el país es un fenómeno presente y evidente. ¿Qué implicaciones tiene ese hecho para la organización del próximo proceso electoral y cuáles deben ser las políticas institucionales en ese sentido?

En el ámbito de nuestra competencia administrativa-electoral, el IFE realizará sus tareas de fiscalización de manera exhaustiva y cuidadosa, siempre procurando la equidad, la transparencia y la legalidad en las contiendas. Ahora, y gracias a las modificaciones reglamentarias aprobadas por el Consejo General, contaremos con nuevos ojos y una normatividad clara para llevar a cabo esta función.

A través de los años, el IFE ha adquirido nuevas facultades que han ampliado sus ámbitos de acción. Una de ellas es la fiscalización de los recursos de los partidos políticos y de las agrupaciones políticas nacionales, de los precandidatos y de las organizaciones de observadores electorales. Como se ha mencionado, la reforma constitucional electoral de 2007-2008 dotó al IFE de nuevas atribuciones en materia de fiscalización a los partidos políticos.

La creación de la Unidad de Fiscalización de los Recursos de los Partidos Políticos, órgano técnico con autonomía de gestión que tiene como atribución la revisión y vigilancia de las finanzas de los sujetos obligados en esta materia, se amplió el número de informes que presentan los partidos políticos sobre sus ingresos y gastos y se dispuso que las tareas de fiscalización no estén limitadas por el secreto bancario, fiscal y fiduciario.

Asimismo, la Unidad de Fiscalización emite criterios de contabilidad y registro de operaciones; es responsable de los procedimientos de 
liquidación de los partidos que pierden su registro; celebra convenios con los órganos de fiscalización de los estados para superar el secreto bancario, fiscal y fiduciario, e inicia procedimientos sancionadores en contra de los sujetos obligados por la comisión de conductas irregulares.

Además, recientemente el Consejo General del IFE aprobó una serie de modificaciones al reglamento de fiscalización. Ellas brindarán el sustento para que a partir del primero de enero de 2012, se lleven a cabo nuevos criterios para la revisión contable a los recursos de los partidos políticos.

Así, estos cambios permiten, en su caso, comprobar la procedencia de recursos de origen ilícito en el financiamiento a partidos políticos y candidatos. En esta tarea, es de destacar la firmeza y el compromiso del Instituto Federal Electoral para revisar las finanzas partidarias e imponer las sanciones correspondientes.

Sin embargo, cabe resaltar que el Estado mexicano cuenta con otros mecanismos e instituciones de control y transparencia con relación al fenómeno del crimen organizado. El Poder Ejecutivo, el Poder Legislativo y las instancias de procuración e impartición de justicia también tienen un papel importante que cumplir en el fortalecimiento de nuestra democracia. Por ello, el IFE procurará medidas para privilegiar la seguridad de todos los ciudadanos que participan en el proceso electoral y confiamos que las autoridades respectivas cumplirán con sus funciones para que se instálenlas casillas, y el próximo 1o. de julio de 2012 sea una fiesta cívica en todo el territorio nacional.

\section{5. ¿Cómo describiría el estado del vínculo institucional con el Tribunal Electoral y cuáles son las eventuales "áreas de oportunidad" para mejorarlos?}

La construcción de nuestro modelo electoral determinó la existencia de dos instituciones para tutelar el ejercicio universal de los derechos políticos-electorales de los mexicanos.

Una es el Instituto Federal Electoral, como autoridad administrativa, responsable de la organización de los procesos electorales; otra es el Tribunal Electoral del Poder Judicial de la Federación, como autori- 
dad jurisdiccional que resuelve, en última instancia, las inconformidades de los ciudadanos, partidos políticos o cualquier sujeto regulado.

Hoy el vínculo de ambas instituciones es mucho más fuerte y sólido porque existe una cooperación y respeto a las decisiones que se toman al interior de estas instancias.

El IFE siempre ha sido un órgano que respeta el Estado de derecho y la autonomía de los órganos jurisdiccionales. Por ello, en estricto apego a lo que mandata la legislación electoral federal, ha cumplido y seguirá cumpliendo en los términos establecidos por la autoridad jurisdiccional cada una de las decisiones y sentencias que por vía de acatamiento le son ordenadas.

La defensa de la legalidad y de la certeza jurídica son premisas que fortalecen la relación del Instituto Federal Electoral con el Tribunal Electoral del Poder Judicial de la Federación, aun cuando los criterios en los cuales se pronuncie una y otra instancia sean distintos, ello no ha sido obstáculo para la construcción de nuevos razonamientos que orientan la resolución y análisis de los temas y asuntos que son puestos a la competencia de estos órganos.

Por tal razón, es necesario fortalecer los puentes de comunicación con la Sala Superior del Tribunal Electoral del Poder Judicial de la Federación, buscando la retroalimentación en la información jurídica que procesa para que todos los involucrados conozcan los criterios en los diversos temas que seguramente tendrán impacto en el próximo proceso electoral.

16. ¿Qué se espera de la ciudadanía, los medios de comunicación, los partidos políticos, sus candidatos y los poderes públicos frente a la próxima elección?

Respeto a la ley y participación.

A raíz del momento que vive nuestra democracia y de las condiciones políticas, económicas y de seguridad que experimente el país, se espera que las y los ciudadanos mexicanos acudirán a las urnas el próximo 1o. de julio de 2012, a efecto de ejercer su derecho al sufragio y ratifiquen su decisión a favor de consolidar nuestra democracia en un ambiente de paz social y civilidad. 
Con independencia del pluralismo que caracteriza a la sociedad mexicana y de las diferencias normales que la alimentan, el Instituto Federal Electoral mantiene su confianza en que los partidos políticos y sus candidatos, así como los sujetos regulados por la Constitución y la legislación electoral vigente, cumplirán con el marco legal vigente y asumirán el compromiso democrático de promover una amplia participación en las elecciones federales del siguiente año.

Esperamos que la ciudadanía incremente su participación, como observadores de la organización de las elecciones, como funcionarios de mesas directivas de casilla, como electores en la jornada electoral, reflexivos ante las propuestas de los candidatos a cargo de elección popular.

De los medios de comunicación se espera equidad en el trato a los partidos políticos y sus candidatos, y cumplimiento puntual, como lo han hecho desde 2009, a las disposiciones del modelo de comunicación política. Por su parte, el IFE aplicará la ley dentro de su ámbito de competencia, organizará elecciones apegadas a derecho, actuará con absoluta transparencia y ofrecerá una rendición de cuentas a satisfacción de quienes participan en los procesos electorales y por supuesto, de la sociedad mexicana.

\section{7. ¿Cómo se prepara el IFE para la elección presidencial de 2012?}

Se está mejorando la planeación, los procedimientos administrativos se están fortaleciendo, el servicio profesional y se está avanzando en las decisiones que el Consejo General puede tomar para disminuir la tensión del proceso electoral y contribuir a la certeza jurídica del proceso electoral.

Por ejemplo, la Estrategia de Capacitación nunca antes en la historia del IFE se había aprobado con la anticipación que se hizo, ahora la aprobamos 3 meses antes del proceso electoral, lo cual no es cosa menor. No olvidemos que esta estrategia fue impugnada en 2006 por el retraso que tuvo en su aprobación, y eso tuvo implicaciones múltiples en los diferentes procesos que estaban en marcha.

Otra medida que se tomó para dar la mayor certeza jurídica y la transparencia en la toma de decisiones del IFE, es la modificación de 
nuestras normas reglamentarias. Con el ánimo de no generar modificaciones que alteraran las condiciones de la contienda, las precisamos antes de que se cumplieran los tres meses establecidos para reformas centrales en materia electoral.

Nosotros estamos claros que la modificación de nuestra reglamentación interna no es una reforma electoral, ni mucho menos es una reforma de fondo. No obstante, lo que estamos haciendo es tratar de dar la mayor certeza para que todos los involucrados, como las instancias jurisdiccionales pudieran revisar nuestras decisiones, y tengamos el mayor elemento de certeza jurídica, y fue así como aprobamos diversos reglamentos y normas reglamentarias.

Una de las reformas reglamentarias que mayores implicaciones ha tenido, es la que tiene que ver con el modelo de comunicación política. Atendiendo al hecho de que no se logró una reforma electoral que modificara el concepto de ciudadanía de la llamada espotización, lo que en el IFE consideramos es que debe haber un mayor dinamismo en las campañas electorales, lo que favorece tanto a los actores políticos como a los ciudadanos.

Como ya lo había mencionado anteriormente, el IFE prepara a sus funcionarios de manera expresa, a falta de una modificación legislativa, el instituto se vio en la necesidad de adecuar vía reglamentaria, la manera que se recuentan los paquetes electorales en caso de que sea necesario, para garantizar que, independientemente del número de paquetes que se tengan que recontar de las tres elecciones federales de 2012, presidencia, senadores y diputados, se concluya en los plazos previstos por la ley.

En resumen, el IFE se prepara previendo con base en la experiencia de 2009, las condiciones de mayor imparcialidad posible para darle certeza y equidad a la contienda.

18. ¿Cuál ha sido el balance de la operación del nuevo modelo de comunicación política, principalmente en la órbita de las entidades federativas que han llevado a cabo elecciones?

El aspecto central del nuevo modelo de comunicación política implementado a raíz de la reforma electoral 2007-2008, fue el nuevo régimen de prerrogativas, en el que les fue otorgado a los partidos políticos el derecho a difundir sus mensajes políticos y electorales a través 
de los tiempos de que dispone el Estado en todas las estaciones de radio y canales de televisión del país, por lo que les garantiza el derecho al acceso gratuito a los medios de comunicación tanto en los periodos electorales como fuera de ellos.

De 2008 a 2011, el IFE ha administrado los tiempos electorales en 38 entidades con procesos electorales. Así como en 12 elecciones extraordinarias.

El balance del nuevo modelo ha sido en todo positivo, algunos aspectos puntuales de su funcionamiento son los siguientes:

- Se instaló y puso en operación un sistema satelital para la transmisión de los promocionales a las televisoras de todo el país y un sitio de Internet para la radio.

- Un sistema automático de control de calidad de los promocionales entregados por los partidos y autoridades.

- Un sistema informático para la aceptación, el control, el tráfico y el envío de los promocionales a cada canal y a cada estación de radio. Este sistema dota de una huella única a los promocionales para luego ser detectada por la tecnología de verificación.

- Se instaló un Centro Nacional de Monitoreo donde se procesa, resguarda y generan los reportes sobre el conjunto de detecciones recibidas por el sistema en el país.

- 150 Centros de Verificación en igual número de distritos en toda la República, donde se detectan los promocionales y se depura la información.

- Cada partido puede elegir su ritmo de campaña y sus tácticas electorales, lo mismo en el ámbito federal que en el local. Cada partido pudo elegir en libertad su estrategia de comunicación (número de promocionales, variedad, temporalidad, alcance geográfico de sus mensajes, etcétera).

- El IFE, mediante su monitoreo, cuenta con el respaldo y los testigos que provienen de los promocionales detectados.

- En el curso de las campañas, cada partido político puede acceder al sistema de monitoreo y directamente al CENACOM, para verificar la adecuada transmisión de sus prerrogativas en la radio y la televisión, desde el Distrito Federal y en las 32 entidades de la República.

- Gracias a su monitoreo, el IFE está en condiciones de demostrar las irregularidades y fundar las diversas sanciones a quienes in- 
fringen la ley. Toda denuncia fundada encuentra su respaldo en los testigos del monitoreo del IFE.

- Gracias al monitoreo es posible tener una radiografía amplia del comportamiento efectivo de los medios de comunicación electrónica en todo el país.

- Con estas medidas, el IFE se constituyó efectivamente en autoridad plena para la administración de los tiempos del Estado en materia electoral, ordenando y haciendo respetar las pautas que señala la ley.

- Debido a que las pautas se construyen con criterios constitucionales, la equidad en la emisión de los promocionales de los partidos políticos está absolutamente garantizada. De manera correlativa: lo que el IFE ordena transmitir a través de sus pautas es verificado y corroborado por el sistema de monitoreo. Este hecho genera un contexto de exigencia favorable para el cabal cumplimiento de los concesionarios y permisionarios.

- Todo lo anterior ha demostrado la viabilidad práctica del nuevo modelo constitucional de comunicación política y electoral en México. 